\title{
Inhibitors of thymidylate synthase and dihydrofolate reductase potentiate the antiviral effect of acyclovir
}

\author{
Mark N. Prichard ${ }^{a, b, 1}$, Lynn E. Prichard ${ }^{a, 2}$ and Charles Shipman, Jr. ${ }^{a, b}$ \\ Department of Biologic and Materials Sciences, School of Dentistry ${ }^{\mathrm{a}}$, The University of Michigan, \\ Ann Arbor, MI 48109, USA and Department of Microbiology and Immunology, \\ Medical School ${ }^{b}$, The University of Michigan, Ann Arbor, MI 48109, USA
}

(Received 2 September 1992; accepted 29 October 1992)

\section{Summary}

In cells infected with herpes simplex virus type 1, intracellular dNTP pools increased markedly. Treatment of these cells with $3 \mu \mathrm{M}$ acyclovir resulted in an additional expansion in pyrimidine deoxyribonucleoside triphosphate pools with dTTP increasing 32-fold and dCTP 8-fold. Both thymidine and deoxycytidine, however, compete with acyclovir for phosphorylation by the viral pyrimidine deoxyribonucleoside kinase and thus reduce the amount of drug that is anabolized to the active form. Theoretically, agents which inhibit thymidylate synthase or dihydrofolate reductase should reduce intracellular pools of thymidine, resulting in the potentiation of the antiviral effects of acyclovir. We explored this strategy by quantitating the synergy produced by combinations of acyclovir and other drugs using three-dimensional doseresponse surface methodology (MacSynergy ${ }^{(i i) ~ I I) . ~ S i g n i f i c a n t ~ s y n e r g y ~ w a s ~ s e e n ~}$ with both 5-FdUrd and methotrexate whereas BrVdUrd, 5-CldUrd, 5-IdUrd, and 5-BrdUrd exhibited little to no synergistic activity. It is suggested that inhibitors of thymidylate synthase and dihydrofolate reductase warrant further exploration as potentiators of acyclovir.

Acyclovir; Synergy; Thymidylate synthase; Dihydrofolate reductase; Fluorodeoxyuridine; Methotrexate

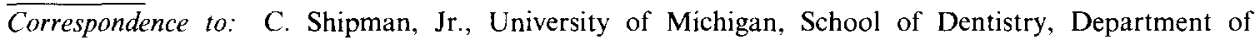
Biologic and Materials Sciences, Ann Arbor, MI 48109-1078 USA.

${ }^{\text {I}}$ Present address: Stanford University, School of Medicine, Dept. Microbiology and Immunology, Stanford, CA 94305-5402, USA.

${ }^{2}$ Present address: Dept. Gynecology and Obstetrics, Stanford University, Medical Center, Stanford, CA 94305-5317, USA. 


\section{Introduction}

Of the drugs currently available for use in the United States, acyclovir (ACV, acycloguanosine, Zovirax $^{\mathbb{R}}$ ) is now established as an effective and welltolerated therapeutic agent for the management of many herpes simplex virus (HSV) and varicella-zoster virus (VZV) infections in both immunocompetent and immunocompromised patients (Reardon and Spector, 1991). The biochemical basis for the high degree of selectivity of ACV is a result of differences that exist between herpesvirus-encoded and cellular enzymes. ACV is selectively phosphorylated by the HSV-encoded pyrimidine deoxyribonucleoside kinase (TK) to the level of the monophosphate (Jamieson et al., 1974; Elion et al., 1977). Cellular kinases further phosphorylate ACV monophosphate to the level of the triphosphate (ACVTP) which is the active form of the drug (Miller and Miller, 1980). Incorporation of ACVTP by the HSV DNA polymerase results in the apparent inactivation of this enzyme (Reardon and Spector, 1989). The sequential selectivity of phosphorylation and incorporation result in specific inhibition of viral DNA synthesis.

The ability of ACV to inhibit virus replication, however, is dependent on its ability to compete with pyrimidine deoxyribonucleosides for initial phosphorylation by the viral TK (Harmenburg, 1983). Both infection with HSV-1 and treatment with ACV dramatically increase intracellular pyrimidine deoxyribonucleoside pools and consequently limit the efficacy of ACV (Cheng et al., 1975; Cheng and Ostrander, 1976; Furman, 1982; Harmenburg, 1983; Karlsson et al., 1988). To counteract this effect, intracellular pyrimidine deoxyribonucleoside pools could be suppressed to increase the activation of ACV. Theoretically, any compound which reduces intracellular pyrimidine deoxyribonucleoside pools could potentiate the antiviral effect of $\mathrm{ACV}$.

To test this hypothesis, we evaluated combinations of ACV and agents which depress intracellular pyrimidine deoxyribonucleoside pools. Since inhibitors of thymidylate synthase (TS) and dihydrofolate reductase (DHFR) deplete deoxypyrimidine pools, we chose inhibitors of these enzymes as candidate agents. Some members of the 5-halogenated deoxyuridine series inhibit TS and have been shown to reduce intracellular thymidine pools at nontoxic concentrations (Heidelberger, 1975). Additionally, E-5-(2-bromovinyl)-1-2'deoxyuridine (BrVdUrd), an inhibitor of TS, was evaluated in combination with $\mathrm{ACV}$. In a manner analogous to $\mathrm{ACV}$, BrVdUrd is selectively phosphorylated to the $5^{\prime}$-monophosphate by the virus-encoded TK (Balzarini et al., 1987). Methotrexate (MTX), a folate analog known to reduce intracellular pools of thymidine through the inhibition of DHFR (Hryniuk, 1975), was also evaluated in combination with ACV.

The experiments presented in this communication reveal that as predicted, inhibitors of both thymidylate synthase and dihydrofolate reductase potentiate the antiviral effect of ACV. 


\section{Materials and Methods}

\section{Chemicals}

ACV was provided through the courtesy of Dr. Sandra Lehrman of the Burroughs Wellcome Company, Research Triangle Park, NC. MTX, 5fluorodeoxyuridine (5-FdUrd), 5-chlorodeoxyuridine (5-CldUrd), 5-bromodeoxyuridine (5-BrdUrd), and 5-iododeoxyuridine (5-IdUrd) were obtained from Sigma Chemical Company (St Louis, MO). HPLC-grade $\mathrm{KH}_{2} \mathrm{PO}_{4}$ was obtained from ICN Biomedical, Costa Mesa, CA.

\section{Cell lines and viruses}

BS-C-1 cells, an established line of African green monkey kidney cells, were grown in monolayers in minimal essential medium with Earle salts [MEM(E)] supplemented with $10 \%$ calf serum as described previously (Prichard et al., 1990 ). Cells were routinely passaged with $0.05 \%$ trypsin plus $0.02 \%$ EDTA in HEPES-buffered saline (HBS) (Shipman, 1969). The KOS strain of HSV-1 was obtained from Dr. Sandra Weller at the University of Connecticut, Farmington, CT. The virus was grown and titered as described previously (Prichard et al., 1990).

\section{Deoxyribonucleoside triphosphate pool determinations}

Triplicate $162 \mathrm{~cm}^{2}$ flasks (Costar ${ }^{(\mathrm{K})}$, Cambridge, MA) containing exponentially growing BS-C-1 cells were passed $12 \mathrm{~h}$ prior to infection and/or drug treatment. Approx. 3-6 × $10^{6}$ exponentially growing BS-C-1 cells were infected with the KOS strain of HSV-1 at a multiplicity of infection of 10 . Drugs were added, following a $1 \mathrm{~h}$ adsorption period. $6 \mathrm{~h}$ post-infection, the cells were washed twice with $\mathrm{HBS}$ at $37^{\circ} \mathrm{C}$ and trypsinized as described above. The extraction protocol is based on the procedure described previously (Garret and Santi, 1979). Briefly, the cells were pelleted and $75 \mu \mathrm{l}$ of ice cold $0.6 \mathrm{M}$ trichloroacetic acid (TCA) and an internal standard of $\left[{ }^{3} \mathrm{H}\right] \mathrm{dTh}$. was added to the cell pellet. The cells were extracted for a minimum of $15 \mathrm{~min}$ on ice and the solution was filtered through a $0.22 \mu \mathrm{M}$ SPIN-X centrifuge filter unit (Costar ${ }^{\mathrm{K}}$, Cambridge, MA) at $4^{\circ} \mathrm{C}$. The TCA was extracted from the solution by adding $125 \mu \mathrm{l}$ of freon with $0.5 \mathrm{M}$ trioctylamine to the filtrate and vortexing. The upper aqueous phase containing the deoxyribonucleoside triphosphates was aliquoted and frozen at $-77^{\circ} \mathrm{C}$.

Ribonucleotides were cleaved via a periodate oxidation reaction (personal communication by Dr. Donald Nelson, Burroughs Wellcome Company, Research Triangle Park, NC). Briefly, to each sample $8 \mu \mathrm{l}$ of $0.25 \mathrm{M}$ sodium metaperiodate (Fisher Scientific, Fair Lawn, NJ) was added and vortexed. Following a $4 \mathrm{~min}$ incubation period at $20^{\circ} \mathrm{C}, 10 \mu \mathrm{l}$ of $4 \mathrm{M}$ methylamine phosphate ( $\mathrm{pH} \mathrm{7.5)} \mathrm{was} \mathrm{added,} \mathrm{vortexed} \mathrm{and} \mathrm{incubated} \mathrm{for} 30 \mathrm{~min}$ at $37^{\circ} \mathrm{C}$. The reaction was stopped by adding $10 \mu \mathrm{l}$ of both $1 \mathrm{M} \mathrm{HCl}$ and $1 \mathrm{M}$ glucose and the samples were frozen at $-77^{\circ} \mathrm{C}$ until separation by HPLC. The dNTPs were separated with a Spectraphysics HPLC (Spectraphysics, San Jose, CA) on a 4.6 
$\mathrm{mm} \times 25 \mathrm{~cm}$ ultrasil AX column with a $3.2 \mathrm{~mm} \times 4.5 \mathrm{~cm}$ ultrasil AX precolumn (Beckman Instruments, Fullerton, CA). The column was equilibrated with $0.3 \mathrm{M} \mathrm{KH}_{2} \mathrm{PO}_{4}$ at $\mathrm{pH} 3.75$ and samples were separated with a 5 min isocratic elution at $2 \mathrm{ml} / \mathrm{min}$ with $0.3 \mathrm{M} \mathrm{KH}_{2} \mathrm{PO}_{4}$ at $\mathrm{pH} 3.75$ followed by a $25 \mathrm{~min}$ linear gradient from $0.3 \mathrm{M}$ to $0.75 \mathrm{M}$ at $\mathrm{pH} 3.75$.

\section{Antiviral enzyme immunoassay}

The antiviral enzyme immunoassay utilized is similar to the one described previously (Prichard and Shipman, 1990). Briefly, an EIA was performed in situ in wells of 96 well plates containing the infected cell sheets. The wells werc first blocked with $200 \mu$ HBS with $0.05 \%$ Tween-20 (HBS-T) with $10 \%$ horse serum for $1 \mathrm{~h}$ at $37^{\circ} \mathrm{C}$. The plates were then shaken out and $50 \mu \mathrm{l}$ of a 1:400 dilution of horseradish peroxidase (HRP) conjugated rabbit anti-HSV-I antibodies (Dako, Santa Barbara, CA) in HBS-T supplemented with $10 \%$ horse serum, were then added to each well. Following a $1 \mathrm{~h}$ incubation at room temperature, the plates were washed 4 times with HBS-T. The plates were subsequently developed with $150 \mu \mathrm{l}$ of a substrate solution consisting of $35 \mathrm{mM}$ citric acid, $67 \mathrm{mM} \mathrm{Na}_{2} \mathrm{IIPO}_{4}$ at pH 5.0, $0.005 \%(\mathrm{v} / \mathrm{v}) 30 \% \mathrm{H}_{2} \mathrm{O}_{2}$ and $1 \mathrm{mg} / \mathrm{ml}$ tetramethyl benzidine (TMB; Sigma Chemical, St. Louis, MO). The reaction was stopped with $50 \mu \mathrm{l}$ of $2 \mathrm{M} \mathrm{H}_{2} \mathrm{SO}_{4}$ and read at $450 / 570 \mathrm{~nm}$ in a microplate bio-kinetics reader (Biotek Instruments, Winooski, V'I).

\section{Synergy analysis}

To characterize the drug-drug interactions, a three-dimensional analytical method was performed with shareware developed in our laboratory (MacSyncrgy ${ }^{\circledR}$ II). Earlier versions of this analytical method have been described elsewhere (Prichard and Shipman, 1990; 1992). Briefly, theoretical additive interactions were calculated from the dose-response curves of the individual drugs. This calculated additive surface, which represents the predicted additive interactions, was then subtracted from the experimental surface to reveal regions of greater than expected interaction (synergy). The resulting surface would appear as a horizontal plane at $0 \%$ inhibition above calculated if the interactions were merely additive. Any peaks above this plane would be indicative of synergy. Similarly, any depression below the plane would indicate antagonism.

The $95 \%$ confidence intervals about the experimental dose-response surface were used to evaluate the data statistically. For each point in the plot, if the lower $95 \%$ confidence limit of the experimental data was greater than the calculated additive surface, the synergy was considered to be significant. Conversely, if the upper $95 \%$ confidence limit of the experimental data was less than the calculated additive surface the antagonism was considered to be significant. All plots and values presented here are at the level of $95 \%$ confidence. 
TABLE 1

Effects of HSV-1 infection and acyclovir treatment on intracellular dNTP pools

\begin{tabular}{lcccc}
\hline Drugs & $\begin{array}{l}\text { dCTP } \\
\text { (Pmol/10 cells) }\end{array}$ & $\begin{array}{l}\text { dTTP } \\
\left(\text { Pmol } / 10^{6} \text { cells }\right)\end{array}$ & $\begin{array}{l}\text { dATP } \\
(\text { Pmol/10 cells })\end{array}$ & $\begin{array}{l}\text { dGTP } \\
(\text { Pmol/10 cells })\end{array}$ \\
\hline Uninfected & $69 \pm 13$ & $77 \pm 9$ & $69 \pm 3$ & $25 \pm 5$ \\
HSV-l KOS & $420 \pm 55$ & $2180 \pm 354$ & $146 \pm 12$ & $167 \pm 31$ \\
HSV-1 KOS & $554 \pm 59$ & $2480 \pm 269$ & $261 \pm 37$ & $272 \pm 51$ \\
$3 \mu$ M ACV & & & & \\
\hline
\end{tabular}

\section{Cytotoxicity determinations}

Simultaneous cytotoxicity assays were done as above except that the plates were not infected with virus. Cell growth was quantitated as described previously (Prichard et al., 1991). Briefly, growth of KB cells (an established human cell line derived from an epidermoid carcinoma of the mouth) was quantitated by staining the cell sheet with crystal violet and measuring the bound dye by eluting with $1 \%(\mathrm{v} / \mathrm{v}) \mathrm{HCl}$ in ethanol. The optical density was determined at $570 / 405 \mathrm{~nm}$ in a microplate bio-kinetics reader (Biotek, Winooski, VT). Data were analyzed as described above.

\section{Results}

Deoxyribonucleoside triphosphate pools

HSV-1 infection significantly increased each of the intracellular dNTP pools with dTTP increasing 28-fold and dCTP increasing 6-fold (Table 1). When infected cells were treated with $3 \mu \mathrm{M} \mathrm{ACV}$, dTTP pools increased by 32 -fold and dCTP pools by 8 -fold compared with values for uninfected untreated cells. These increases in intracellular pyrimidine dNTPs are consistent with observations published by others (Furman, 1982; Harmenburg, 1983; Karlsson et al., 1988).

TABLE 2

Antiviral activity $\left(\mathrm{IC}_{50}\right)$, cytotoxicity $\left(\mathrm{TC}_{50}\right)$ and potentiation of the antiviral effect of acyclovir by a series of inhibitors of thymidylate synthase and dihydrofolate reductase

Data are presented as the arithmetic mean of two experiments (except as noted)

\begin{tabular}{llll}
\hline Compound name & TC $(50)(\mu \mathrm{M})$ & IC $(50)(\mu \mathrm{M})$ & Synergy with ACV $\left(\mu \mathrm{M}^{2} \%\right)$ \\
\hline ACV & $>100$ & 0.5 & - \\
5-FdUrd & 0.25 & 0.02 & $80^{\mathrm{a}}$ \\
5-CldUrd & 65 & 0.59 & 4 \\
5-BrdUrd & $>100$ & 0.89 & 0 \\
5-IdUrd & 70 & 2.0 & 3 \\
BrVdUrd & $>100$ & 1.2 & 8 \\
MTX & 28 & 0.11 & $47^{\mathrm{a}}$ \\
\hline
\end{tabular}

"Average of three separate experiments. 
Antiviral activity and cytotoxicity

Each of the compounds was evaluated individually in terms of both antiviral effect $\left(\mathrm{IC}_{50}\right)$ and cytotoxicity $\left(\mathrm{TC}_{50}\right)$. The antiviral activity and cytotoxicity of these compounds are shown in Table 2.

\section{Synergy with ACV and 5-halogenated deoxyuridines}

In the 5-halogenated deoxyuridine series, 5-FdUrd clearly was the best potentiator of ACV in terms of antiviral activity (Table 2). The average volume of synergy produced by this combination was $80 \mu \mathrm{M}^{2} \%$ at a level of confidence of $95 \%$. The results from a typical experiment are shown in Fig. 1. In this experiment, the synergy had a volume of $34 \mu \mathrm{M}^{2} \%$ at $95 \%$ confidence (Fig. 1A) and the optimal drug concentrations were $0.37 \mu \mathrm{M} \mathrm{ACV}$ and $0.014 \mu \mathrm{M} 5$ FdUrd (Fig. 1B). This appeared to be a specific antiviral effect as no significant synergistic cytotoxicity was observed (data not shown). The other compounds

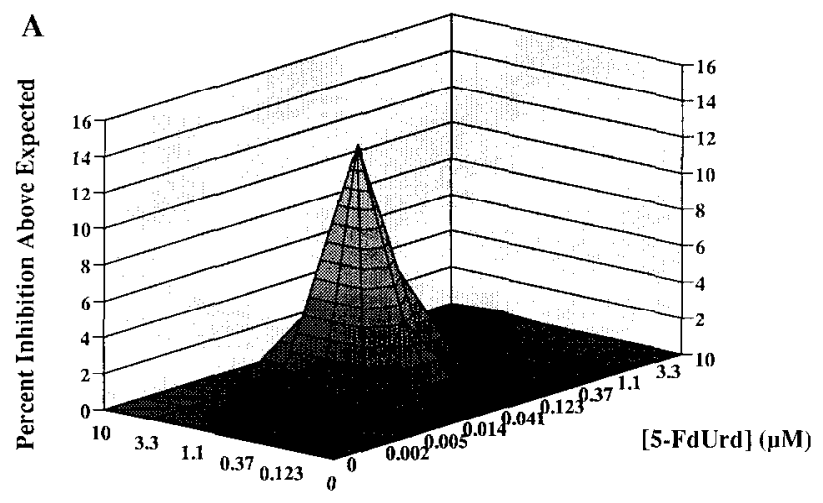

$[\mathrm{ACV}](\mu \mathrm{M})$

B

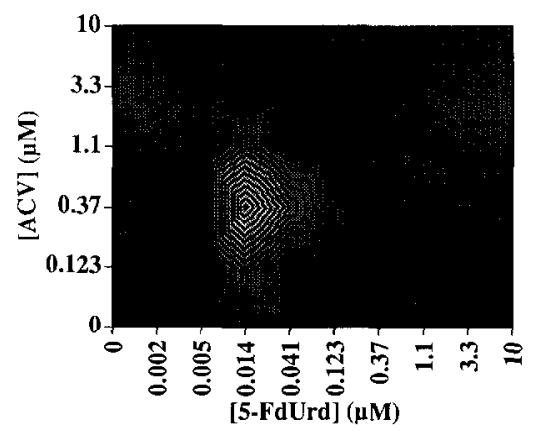

Fig. 1. Synergistic antiviral interactions with combinations of acyclovir and 5-fluorodeoxyuridine (5FdUrd). The synergy plot in both three-dimensional $(A)$ and contour form (B) reveals the antiviral synergy produced by ACV and 5-FdUrd at the $95 \%$ level of confidence. In the representative experiment shown here, the volume of synergy produced by this combination had a volume of $34 \mu \mathrm{M}^{2} \%$ at $95 \%$ confidence.

Maximal synergy was observed at $0.37 \mu \mathrm{M} \mathrm{ACV}$ and $0.014 \mu \mathrm{M}$ 5-FdUrd. 
in this series produced little or no significant synergy and we consider the interactions to be negligible (Table 2). Interestingly, in this series of compounds only 5-FdUrd is an inhibitor of TS (De Clercq et al., 1978).

\section{Synergy with $A C V$ and BrVdUrd}

Combinations of BrVdUrd and $\mathrm{ACV}$ showed very little significant synergistic antiviral activity ( $8 \mu \mathrm{M}^{2} \%$ at $95 \%$ confidence). This synergy was not significant at $99 \%$ confidence and we consider these interactions to be negligible. BrVdUrd has been shown to inhibit TS in infected cells, but was unable to potentiate the antiviral effects of ACV. However, unlike the 5halogenated deoxyuridines, BrVdUrd is phosphorylated exclusively by the viral TK and competes with ACV for phosphorylation (Balzarini et al., 1987). This competition may overcome the possible benefit of reducing deoxypyrimidine pools in infected cells.

\section{Synergy with $A C V$ and $M T X$}

Pyrimidine deoxyribonucleoside pools can also be suppressed with folic acid analogs. Significant synergistic antiviral interactions were seen with the combination of MTX and ACV and had an average volume of $47 \mu \mathrm{M}^{2} \%$ at $95 \%$ confidence (Table 2 ). The results from a typical experiment are shown in Fig. 2. In this experiment, the volume of synergy produced was $40 \mu \mathrm{M}^{2} \%$ at 95\% confidence (Fig. 2A). The optimal drug concentrations were $0.37 \mu \mathrm{M}$ ACV and $0.123 \mu \mathrm{M}$ MTX (Fig. 2B). Again this appeared to be a specific antiviral effect as no synergistic cytotoxicity was observed (data not shown).

\section{Discussion}

Previous reports have demonstrated that high levels of thymidine reduce the efficacy of ACV by competing for phosphorylation by the HSV TK (Harmenberg, 1983). In the present report, we demonstrate that agents which suppress intracellular pyrimidine deoxyribonucleoside pools by inhibiting thymidylate synthase or dihydrofolate reductase significantly increase the efficacy of ACV.

We examined the ability of a series of compounds to potentiate the antiviral effects of ACV. In the 5-halogenated deoxyuridine series, only 5-FdUrd was able to potentiate the antiviral effect of ACV. In this series only 5 -FdUrd is a potent inhibitor of TS and results in decreased pyrimidine deoxyribonucleoside pools (De Clercq et al., 1978; Descamps et al., 1982). The structure-synergy relationship observed here correlates well with the TS inhibition produced by halogenated deoxyuridines and supports the hypothesized mechanism of synergy. MTX reduces intracellular pyrimidine deoxyribonucleoside pools through a different mechanism (inhibition of DHFR) (Hryniuk, 1975). As predicted, this drug also efficiently potentiated the antiviral effects of ACV. As with 5-FdUrd, the synergy is most likely mediated by the depression of 


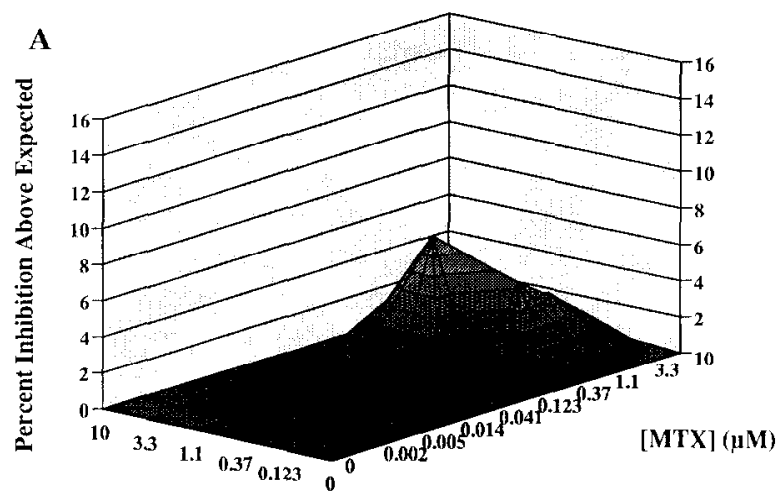

[ACVI (uM)

$\mathbf{B}$

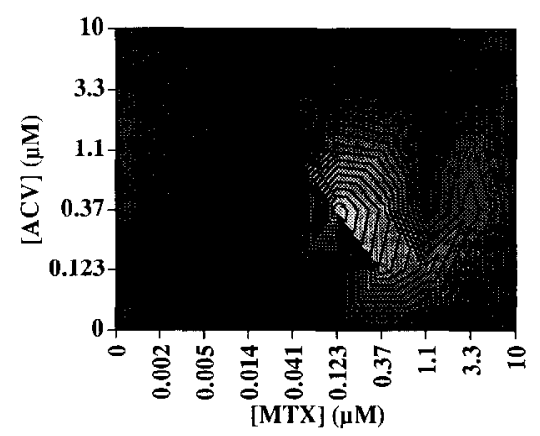

Fig. 2. Synergis . antiv 1 interactions with combinations of acyclovir and the folate analog methotrexate (MTX). The synergy plot in both three-dimensional (A) and contour form (B) reveals the antiviral synergy produced by ACV and MTX at the $95 \%$ level of confidence. In the representative experiment shown here, the volume of synergy produced by this combination was $40 \mu \mathrm{M}^{2 \%}$ at $95 \%$ confidence. Maximal synergy was observed at $0.37 \mu \mathrm{M} \mathrm{ACV}$ and $0.123 \mu \mathrm{M} \mathrm{MTX}$.

pyrimidine deoxyribonucleoside pools and a corresponding increase in the level of ACV phosphorylation.

We conclude that the antiviral effect of ACV can be potentiated by drugs that are capable of inhibiting either thymidylate synthase or dihydrofolate reductase. In the case of TS, an earlier observation by Cheng and coworkers (1983) demonstrated that 5-FdUrd and ACV appeared to interact synergistically at the single concentrations studied. Structure-synergy relationships in the halogenated deoxyuridine series correlated well with TS inhibition by the individual agents. The single exception to this rule was BrVdUrd. BrVdUrd is known to inhibit TS in HSV-infected cells and yet did not potentiate the antiviral effect of ACV. Unlike the 5-halogenated deoxyuridines, BrVdUrd is phosphorylated exclusively to the active form (BrVdUrd monophosphate) by the HSV TK. Consequently, BrVdUrd competes with ACV for activation by 
the HSV TK and probably results in reduced phosphorylation of either ACV, BrVdUrd, or both drugs. This competition may overcome the possible benefit of reducing pyrimidine deoxyribonucleoside pools in infected cells.

Several reports have shown that the suppression of intracellular deoxyguanosine triphosphate (dGTP) pools by inhibitors of the HSV ribonucleotide reductase potentiate the antiviral effects of ACV (Spector et al., 1985; 1987; $1989 ; 1991)$. In this report, we show that it is also possible to potentiate the antiviral effects of ACV through TS or DHFR inhibition. This strategy was effective in inhibiting the replication of herpes simplex virus and should be even more effective against varicella-zoster virus which encodes a distinct TS.

Reducing intracellular dGTP pools results in the potentiation of $\mathrm{ACV}$ (Spector et al., 1985; 1987; 1989; 1991). It is also possible to potentiate ACV with inhibitors of TS or DHFR, presumably by reducing intracellular pyrimidine deoxyribonucleoside pools. These two mechanisms of ACV potentiation are not mutually exclusive and both of these strategies could be used simultaneously to optimize the efficacy and selectivity of ACV. In fact, a three-drug combination that utilizes both of these mechanisms has been shown to be a very potent inhibitor of viral replication (Prichard et al., submitted). The potentiation produced by this strategy was shown to be superior to the potentiation produced by either inhibitors of the HSV ribonucleotide reductase or by inhibitors of TS.

The structure-synergy relationships established here suggest that the reduction of intracellular pyrimidine deoxyribonucleoside pools could potentiate the antiviral effects of $\mathrm{ACV}$. These experiments identified the most potent drug combination against HSV and identified optimal drug concentrations. We propose that inhibitors of thymidylate synthase and dihydrofolate reductase warrant further exploration as potentiators of acyclovir.

\section{Acknowledgements}

We thank Kimberly R. Aseltine for assistance in the construction of threedimensional dose-response surfaces. This work was supported by Public Health Service grant DE-08510 from the National Institute of Dental Research and by Public Health Service grant AI-05077 from the National Institute of Allergy and Infectious Diseases.

\section{References}

Balzarini, J., De Clercq, E., Verbruggen, A., Ayusawa, D., Shimizu, K. and Seno, T. (1987) Thymidylate synthase is the principal target enzyme for the cytostatic activity of (E)-5-(2bromovinyl)-2'-deoxyuridine against murine mammary carcinoma (FM3A) cells transformed with the herpes simplex virus type 1 or type 2 thymidine kinase gene. Mol. Pharmacol, 32, 410 416.

Cheng, Y.-C., Goz, B. and Prusoff, W.H. (1975) Deoxyribonucleotide metabolism in herpes simplex 
virus infected HeLa cells. Biochim. Biophys. Acta 390, 253-263.

Cheng, Y.-C. and Ostrander, M. (1976) Deoxythymidine kinase induced in HeI a TK ${ }^{-}$cells by herpes simplex virus type 1 and type 2. J. Biol. Chem. 251, 2605-2610.

Cheng, Y.-C., Nakayama, K. and Grill, S.P. (1978) Roles of thymidylate synthetase activity in herpes simplex virus-infected HeLa cells. Biochem. Pharmacol. 32, 1407-1410.

De Clercq, E., Descamps, J., Huang, G.-F. and Torrence, P.F. (1978) 5-nitro-2'-deoxyuridine and 5 nitro-2'-deoxyuridine 5'-monophosphate: Antiviral activity and inhibition of thymidylate synthetase in vivo. Mol. Pharmacol. 14, 422-430.

Deschamps, J., Sehgal, R.H., De Clercq, E. and Allaudeen, H.S. (1982) Inhibitory effect of E-5-(2bromovinyl)-1- $\beta$-D-arabinofuranosyluracil on herpes simplex virus replication and DNA synthesis. J. Virol. 43, 332-336.

Furman, P.A., Lambe, C.U. and Netson, D.J. (1982) Effect of acyclovir on the deoxyriborlucleotide triphosphate pool levels in vero cells infected with herpes simplex virus type 1. Am. J. Med. $73(1 \mathrm{~A}), 14-17$

Garret, C. and Santi, D.V. (1979) $\Lambda$ rapid and sensitive high-pressire liquid chromatography assay for deoxyribonucleoside triphosphates in cell extracts. Analytical Biochem. 99, 268-273.

Harmenberg, J. (1983) Intracellular pools of thymidine reduce the antiviral action of acyclovir. Intervirology 20, 48-51.

Heidelberger, C. (1975) Fluorinated pyrimidines and their nucleosides. In: A.C. Sartorelli and D.G. Johns (Eds), Handbook of experimental pharmacology. Vol. 38, part 2, pp. 193-231, SpringerVerlag, New York.

Hryniuk, W.M. (1975) The mechanism of action of methotrexate in cultured L5178Y leukemia cells. Cancer Res. 35, 1085-1092.

Jamieson, A.T., Gentry, G.A. and Subak-Sharpe, J.H. (1974) Induction of both thymidine and deoxycytidine kinase activity by herpes viruses. J. Gen. Virol. 24, 465-480.

Karlsson, A. and Harmenberg, J.G. (1988) Effects of ribonucleotide reductase inhibition on pyrimidine metabolism in acyclovir-treated cells infected with herpes simplex virus. Antimicrob. Agents Chemother. 32, 1100-1102.

Miller, W.H. and Miller, R.L. (1980) Phosphorylation of acyclovir (acycloguanosine) monophosphate by GMP kinase. J. Biol. Chem. 255, 7204-7207.

Prichard, M.N. and Shipman, C. Jr. (1992) Letter to the editor in response to J. Sühnel's comment on the paper, 'A three-dimensional model to analyze drug-drug interactions.' Antiviral Res. 17, 95-98.

Prichard, M.N. and Shipman, C. Jr. (1990) A three-dimensional model to analyze drug-drug interactions. Antiviral Res. 14, 181-206.

Prichard, M.N., Prichard, L.E., Baguley, W.A., Nassiri, M.R. and Shipman, C. Jr. (1991) Threedimensional analysis of the synergistic cytotoxicity between ganciclovir and zidovudine. Antimicrob. Agents Chemother. 35, 1060-1065.

Prichard, M.N., Turk, S.R., Coleman, L.A., Engelhardt, S.L., Shipman, C. Jr. and Drach, J.C. (1990) A microtiter virus yield reduction assay for the evaluation of antiviral compounds against human cytomegalovirus and herpes simplex virus type 1. J. Virol. Methods 28, 101-106

Reardon, J.E. and Spector, T. (1989) Herpes simplex virus type 1 DNA polymerase: mechanism of inhibition by acyclovir triphosphate. J. Biol. Chem. 264, 7405-7411.

Reardon, J.E. and Spector, T. (1991) Acyclovir: mechanism of antiviral action and potentiation by ribonucleotide reductase inhibitors. Adv. Pharmacol. 22, 1-27.

Shanley, J.D. and Debs, R.J. (1989) The folate antagonist, methotrexate, is a potent inhibitor of murine and human cytomegalovirus in vitro. Antiviral Res. 11, 99-106.

Shipman, C. Jr. (1969) Evaluation of 4-(2-hydroxyethyl)-1-piperazineëthanesulfonic acid (HEPES) as a tissue culture buffer. Proc. Soc. Exp. Biol. 130, 305-310.

Spector, T., Averett, D.R., Nelson, D.J., Lambe, C.U., Morrison, R.W. Jr., St.Claire, M.H. and Furman, P.A. (1985) Potentiation of antiherpetic activity of acyclovir by ribonucleotide reductase inhibition. Proc. Natl. Acad. Sci. USA 82, 4254-4257.

Spector, T., Stonehuener, J.G., Biron, K.K. and Averett, D.R. (1987) Ribonucleotide reductase induced by varicella zoster virus: characterization, and potentiation of acyclovir by its inhibition 
Biochem. Pharmacol. 36, 4341-4346.

Spector, T., Harrington, J.A. and Porter, D.J.T. (1991) Herpes and human ribonucleotide reductases, inhibition by 2 -acetylpyridine 5-[(2-chloroanalino)-thiocarbonyl] thiocarbonohydrazone (348U87). Biochem. Pharmacol. 42, 91-96.

Spector, T., Harrington, J.A., Morrison, R. Jr., Lambe, C.U., Nelson, D.J., Averett, D.R., Biron, K. and Furman, P.A. (1989) 2-Acetylpyridine 5-[(dimethylamino)thiocarbonyl]-thiocarbonohydrazone $(A 1110 \mathrm{U})$, a potent inactivator of ribonucleotide reductases of herpes simplex and varicella-zoster viruses and a potentiator of acyclovir. Proc. Natl. Acad. Sci. USA 86, 10511055.

Thompson, R., Honess, R.W., Taylor, L., Morran, J. and Davison, A.J. (1987) Varicella-Zoster virus specifies a thymidylate synthetase, J. Gen. Virol. 68, 1449-1455. 